\title{
AWARENESS \& APPLICATIONS OF ARTIFICIAL INTELLIGENCE TOOLS FOR MANAGEMENT STUDENTS
}

\author{
Dr. Kavita Khadse \\ Assistant Professor, Department of Information Technology/Systems, Chetana's Ramprasad \\ Khandelwal Institute of Management \& Research, Affiliated to Mumbai University, Mumbai, \\ Maharashtra, India
}

\begin{abstract}
:
With the Industry Revolution 4.0, Artificial Intelligence (AI) is bound to have its contribution in almost all of the sectors. AI has been constantly contributing to improvements in ability and performance of the systems and the services, with many of the sectors already benefiting from AI. It has also made a noteworthy progress in education sector. The paper analyses awareness of AI tools introduced for voice assistance which are being used by a major population of management students. It checks if there is any variation in the awareness level of the students based on demographic classification. It also provides potential impact of AI with variation in the levels of awareness among management students. Paper provides a broad overview about the benefits of incorporating AI in Management Education Sector.
\end{abstract}

KEYWORDS: Industry Revolution 4.0, Artificial Intelligence, Education Sector, AI tools, Voice Assistance, Management Education

Article Received: 10 August 2020, Revised: 25 October 2020, Accepted: 18 November 2020

\section{INTRODUCTION}

The arising advancements viz. web of things (IoT), information science, large information, distributed computing, man-made reasoning (AI), and blockchain are changing the way we live, work and interest ourselves. Further headway of these innovations can contribute in creating. Basically, the headway in AI is the core of the upgraded execution of any remaining advances and the development of Industry 4.0. This mechanical progression, ascribed to AI, would encourage human-to-machine cooperations, change the rationale of plans of action, and change the way of life and expectations for everyday comforts of the human. The examination that fills the AI upheaval has likewise seen quick changes. First among them is the development of AI, animated partially by the ascent of the computerized economy, which both gives and use a lot of information. Different components incorporate the ascent of distributed computing assets and buyer interest for boundless admittance to administrations like discourse acknowledgment and route uphold.

Presently, as it turns into a focal power in the public eye, the field of AI is moving toward building astute frameworks that can work together adequately with individuals, and that are all the more for the most part human-mindful, including inventive approaches to create intuitive and adaptable ways for individuals to educate robots. These hot patterns in the territories of AI investigation into both central techniques and application zones: Large-scale AI concerns the plan of learning calculations, just as scaling existing calculations, to work with very enormous informational collections.

Awareness of such tools among students is of prime importance since AI is predicted to affect the whole of the education system starting from pre-schools up to post graduations. Personalized education has been impacted and further will have a lot of changes due to the advances in technology. AI is helping in carrying out analytical study of the students, thereby enabling professors to take a differentiated teaching approach for every different group of students clubbed together on the basis of results of the analytical studies. Personalized course content for different groups of students has become a key which will help students get a better understanding of the content of the course. Benefits of AI would be available to students even after completing their education as it will help them with the selection of appropriate job roles with personalized suggestions. 


\section{A. AI tools used by Management students:}

In the high-level training environment, advanced education establishments are giving voice associates to the understudies as opposed to the usually printed handbooks or hard to-investigate destinations for assist with different grounds related illuminating necessities. Amazon Alexa is a way to deal with give them extensively more perfect and focused information about their grounds needs. These voice accomplices can help answer standard requests seeing grounds needs similarly as be modified for each understudy's particular schedule and courses. This uncommonly reduces the prerequisite for inside assistance and decreases the cost of wasteful school handbook printing that can quickly get away from date. The use of voice helper structures is a ton of stimulating and interesting to most understudies and is needed to obtain more broad allotment in the coming years.

\section{1) Alexa (Amazon)}

Alexa is a Voice service which makes use of Conversational AI to communicate with people in ways that feel effortless, solve problems, and get smarter over time. Alexa is assembled dependent on normal language handling (NLP), a system of changing over discourse into words, sounds, and thoughts. NLP causes PC machines to participate in correspondence utilizing regular human language in numerous structures, including however not restricted to discourse and composing. Alexa at that point utilizes Natural Language Understanding (NLU) measure, where the meaning / context of the words are determined by breaking them down into smaller samples of individual words which are compared with a pre-fed speech to determine what the user said in each unit of speech. These words are sequenced to make the most likely sentences for Alexa to work upon. Thus, Alexa helps humans to interact with device across the room to play music, get the news, set timers, make hands-free calls, manage to-do and shopping lists, control lights, your thermostat and so much more.

\section{2) Home and Nest (Google)}

For a really long time, the shrewd home hasn't been savvy. It's confounded to set up and oversee, with many gadgets that don't function admirably together. So google is working on things and uniting all Nest and Google Home items under one rooftop. The keen speaker from the eponymous pursuit goliath was intended to contend with the well known Amazon Echo. The Google Home can play music, yet it's basically planned as a vehicle for Google Assistant Google's voice-initiated virtual aide that is associated with the web. The Google Assistant you access through the Home is equivalent to the one on ongoing Android telephones, for example, the Google Pixel 4. When you get your Google Home set up, you might need to utilize it to tune in to music. You can utilize a Google Home as a standard Bluetooth speaker and pull up the melody you need to tune in to on your telephone. Even better, utilize your voice to mention to Google what tune you need to hear. You can even pursuit by verses on the off chance that you don't recollect the name, or advise it to begin a playlist of a specific type.

Google Home has improved as an individual associate. You could generally ask your Google Home to perform fundamental errands like looking through the web and checking your schedule. Presently, Google Assistant in your keen speaker can accomplish such a great deal more. You can prepare Google Assistant to perceive up to six unmistakable voices, which will empower it to tweak its reactions dependent on who's talking. Google would then be able to offer customized answers on the off chance that you get some information about your drive to work or your timetable for the afternoon.

One can add various profiles for every individual from your family and in the event that you need Google Assistant to react to you in a remarkable voice, you have a few alternatives now. Even better, extraordinary relatives can pick various voices, and Google will switch which one reacts dependent on who's talking. With the Continued Conversation highlight, one doesn't need to say the wake words each time you need to pose an inquiry. The Google Home's mouthpiece stays hot for as long as eight seconds so you can ask a subsequent inquiry without saying, "Hello, Google" once more. It'll stop early in the event that you say, "Thank you," and on the off chance that you don't need Google's mic to remain tuning in for more than typical, you don't need to empower the component.

\section{3) Siri (Apple)}

Siri makes it simple for individuals to achieve ordinary undertakings rapidly utilizing voice, contact, or mechanization. At the point when you 
use SiriKit to characterize the assignments and activities that your application underpins, individuals can utilize Siri to perform them in any event, when your application isn't running. In case you're an extra creator, you can likewise help individuals use Siri to control your embellishments by coordinating them. Siri works with your items on iPhone, iPad, Apple Watch, Home Pod, Air Pods, and in CarPlay, so individuals can utilize it all over the place. At the point when you make your application's errands free through Siri, you have a few chances to tweak the client experience. At a major level, you alter the stream and usefulness of the ordinary undertakings and activities you backing to actualize your business necessities. To strengthen this usefulness all through the client experience, you can compose discourse that mirrors the style and tone of your organization's correspondences and plan custom UI that joins your application's visual style into the Siri interface.

At the point when individuals use Siri to pose inquiries and perform activities, Siri does the language preparing and semantic examination expected to transform their solicitations into goals for your application to deal with. The exemption is the individual expression that individuals make to trigger an alternate route: When individuals talk the specific expression, Siri remembers it without doing extra handling or investigation.

An unprecedented voice interface helps people with feeling certain they'll get the results they need, regardless, when they don't have a clue what they can say. Siri supports particular voice experiences for structure gave purposes and custom objectives. With a structure reason, Siri does the trademark language planning for you, permitting people to help out your application in various conversational habits. With a custom objective, your application helps people with playing out a task that Siri doesn't consider yet, which achieves a substitute sort of help for the voice knowledge. Custom purposes give you additional events to change conversational trade, yet furthermore anticipate that individuals should make and talk an accurate articulation to trigger the correspondence. People can use Siri to finish things while they're in a vehicle, working out, using applications on a contraption, or teaming up with Home Pod. You don't by and large know the setting wherein people are using Siri to play out your application's exercises, so flexibility is vital to help people with having an exceptional experience paying little mind to what they're doing.

\section{4) Grammarly (ML based writing tool)}

As you can envision, an intricate AI framework like this one requires a ton of registering power-substantially more than a PC or cell phone can give. Consequently, it runs in the cloud, as opposed to locally on your gadget. All you require to check your composition with a Grammarly item is an Internet association. At the point when you use Grammar, you can help improve its proposals. Whenever you hit "disregard" on a pointless proposal, Grammarly gets somewhat more astute. After some time, our group can make acclimations to the recommendations with high disregard rates to make them more accommodating.

Hidden the entirety of Grammarly's items is a complex man-made brainpower framework worked to break down sentences written in English. Grammarly's group of computational etymologists and profound learning engineers plans front line calculations that become familiar with the principles and concealed examples of good composition by breaking down great many sentences from research corpora. (A corpus is a huge assortment of text that has been coordinated and named for innovative work purposes.) When you compose with Grammarly, our AI breaks down each sentence and searches for approaches to improve it, regardless of whether it's revising an action word tense, proposing a more grounded equivalent, or offering a clearer sentence structure.

\section{5) Turnitin (ML based writing tool)}

In spite of the fact that AI is taking jumps and limits each year, it actually is by all accounts far from taking over innovative errands like chiseling and making music. Notwithstanding, you might be amazed to discover that AI composing is really a reality today.

In any case, it retained the last form in light of the fact that there were "malignant uses of the innovation" however they permitted different creators the opportunity to test and work with it.

So, AI composing is likely nearer than the vast majority think it is. With devices like Heliograph and GPT-2 previously made, all that remains is 
for the tech to turn out to be more open and more reasonable. Indeed, EdTech organizations like Turnitin are now using the advancement of AI and AI in item improvement. It won't be long until understudies will approach AI composing bots and the ideal opportunity for instructors to get ready is currently. Artificial intelligence won't show up on understudies' doorsteps as an enchantment button that says, "Make paper here". It will advance into the creative cycle gradually by offering an ever-increasing number of cutting-edge instruments that remove expanding measures of control from the human creator.

Effectively, mechanized altering instruments can revise sentences, fix complex language structure botches, mention to you what the tone of your composing is, and even propose new sources to take a gander at. It won't be any longer before they can change entire papers, rebuild bigger works, and spot more summed up issues with a piece of composing. For understudies, particularly those battling with their composition, this will probably be a help. It won't mysteriously transform feeble essayists into stunning ones; however, it will help such understudies become better, more decipherable writers. Yet, sooner or later, the instruments will become progressed enough that understudies won't be steering the ship with their own composition. There will come a period that the robotization will have wrestled an excessive amount of control and go from assisting the understudy with composing compose the paper for them

\section{LITERATURE REVIEW}

Worldwide Journal of Educational Technology in Higher Education volume 16, Article number: 39 (2019)

Artificial intelligence and versatile learning innovations are unmistakably included as significant advancements in instructive innovation in the 2018 Horizon report (Educause, 2018), with a chance to reception of 2 or 3 years. As indicated by the report, specialists foresee AI in instruction to develop by $43 \%$ in the time frame 2018-2022, albeit the Horizon Report 2019 Higher Education Edition (Educause, 2019)

With hefty speculations by privately owned businesses like Google, which gained European AI fire up Deep Mind for $\$ 400$ million, and furthermore non-benefit public-private associations, for example, the German Research
Center for Artificial IntelligenceFootnote1 (DFKI), almost certainly, this rush of interest will before long fundamentally affect advanced education organizations (Popenici and Kerr, 2017).

The use of AI in schooling (AIEd) has been the subject of examination for about 30 years. The International AIEd Society (IAIED) was dispatched in 1997, and distributes the International Journal of AI in Education (IJAIED), with the twentieth yearly AIEd gathering being coordinated for the current year. Nonetheless, on a more extensive scale, teachers have quite recently begun to investigate the potential instructive chances that AI applications bear for supporting students during the understudy life cycle.

Russel and Norvig (2010) remind us in their driving course reading on man-made brainpower, "All AI analysts ought to be worried about the moral ramifications of their work" (p. 1020). Hence, we might want to investigate what sort of new moral ramifications and dangers are reflected by the creators in the field of AI upgraded instruction. The point of this article is to give an outline to instructors of examination on AI applications in advanced education. Given the unique improvement as of late, and the developing interest of instructors in this field, an audit of the writing on $\mathrm{AI}$ in advanced education is justified.

In particular, this paper tends to the accompanying examination inquiries in three territories, by methods for a methodical survey (see Gough, Oliver, and Thomas, 2017; Petticrew and Roberts, 2006):

- How have distributions on AI in advanced education created over the long run, in which diaries would they say they are distributed, and where are they coming from as far as geological conveyance and the creator's disciplinary affiliations?

- How is AI in training conceptualized and what sort of moral ramifications, difficulties and dangers are thought of?

- What is the nature and extent of AI applications with regards to advanced education?

The field AI begins from software engineering and designing; however, it is firmly affected by 
different teaches like way of thinking, psychological science, neuroscience, and financial aspects. Given the interdisciplinary idea of the field, there is little arrangement among AI analysts on a typical definition and comprehension of $\mathrm{AI}$ - and insight when all is said in done (see Tegmark, 2018). Concerning the presentation of AI-based devices and administrations in advanced education, Hinojo-Lucena, Aznar-Díaz, Cáceres-Reche, and Romero-Rodríguez (2019) note that "this innovation $[\mathrm{AI}]$ is now being presented in the field of advanced education, albeit numerous instructors are unconscious of its extension and, most importantly, of what it comprises of" (p. 1). With the end goal of our examination of computerized reasoning in advanced education, it is alluring to explain phrasing. Along these lines, in the following segment, we investigate meanings of $\mathrm{AI}$ in schooling, and the components and strategies that AI applications may involve in advanced education, before we continue with the orderly survey of the writing.

The acquaintance of AI gets back with the 1950s when John McCarthy composed a two-month workshop at Dartmouth College in the USA. In the workshop suggestion, McCarthy used the term man-made mental ability unprecedented for 1956 (Russel and Norvig, 2010, p. 17): The assessment [of fake intelligence] is to proceed with dependent on the theory that each piece of learning or some other component of understanding can on a basic level be so certainly depicted that a machine can be made to recreate it. An undertaking will be made to find how to make machines use language, structure reflections and thoughts, deal with kinds of issues presently put something aside for individuals, and create themselves.

Cook and Smith (2019) give a sweeping significance of AI: "Laptops which perform scholarly tasks, ordinarily associated with human characters, particularly learning and basic reasoning" (p. 10). They explain that AI doesn't depict a lone advancement. It is an umbrella term to depict an extent of advances and strategies, for instance, AI, typical language dealing with, data mining, neural associations or an estimation.

Man-made insight and AI are regularly referred to simultaneously. Man-made intelligence is a method for AI for oversaw and solo plan and profiling, for example to predict the likelihood of an understudy to exit from a course or being admitted to a program, or to perceive subjects in created errands. Popenici and Kerr (2017) portray AI "as a subfield of modernized thinking that joins programming prepared to see plans, make gauges, and apply newly discovered guides to conditions that were rejected or covered by their fundamental arrangement" (p. 2).

The possibility of rational experts is key to AI: "An expert is whatever can be viewed as seeing its present situation through sensors and circling back to that environment through actuators" (Russel and Norvig, 2010, p. 34). The vacuum-cleaner robot is an essential kind of a sharp trained professional, yet things become confounding and open-completed when we consider a robotized taxi.

Experts in the field perceive frail and strong AI (see Russel and Norvig, 2010, p. 1020) or restricted and general AI (see Baker and Smith, 2019 , p. 10). A philosophical request remains whether machines will really need to truly think or even make awareness later on, instead of basically copying thinking and showing typical direct. It is doubtful that such strong or general AI will exist in the near future. We are thusly overseeing GOFAI ("common AI", a term founded by the researcher John Haugeland, 1985) in high level training - in the sensation of subject matter experts and information structures that go about like they were keen.

Given this comprehension of AI, what are likely regions of AI applications in training, and advanced education specifically? Luckin, Holmes, Griffiths, and Forcier (2016) portray three classifications of AI programming applications in training that are accessible today: a) individual mentors, b) smart help for shared learning, and c) astute computer generated experience.

Adroit instructing systems (ITS) can be used to duplicate adjusted individual tutoring. Considering understudy models, estimations and neural associations, they can make decisions about the adapting method of an individual understudy and the substance to pick, give mental stage and help, to interface with the understudy in return. ITS have giant potential, especially in tremendous degree distance showing foundations, which run modules with an enormous number of understudies, where human composed coaching is incomprehensible. A gigantic scope of 
investigation shows that learning is a social exercise; affiliation and joint exertion are at the center of the learning connection (see for example Jonassen, Davidson, Collins, Campbell, and Haag, 1995). Regardless, online joint exertion should be energized and coordinated (Salmon, 2000). AIEd can add to aggregate learning by supporting flexible social affair advancement subject to understudy models, by empowering on the web bundle cooperation or by summarizing discussions that can be used by a human mentor to oversee understudies towards the focuses and focuses of a course. Finally, moreover drawing on ITS, sharp PC created recreation (IVR) is used to associate with and direct understudies in legitimate increased insight and game-based learning conditions. Virtual experts can go about as teachers, facilitators or understudies' buddies, for example, in virtual or distant labs (Perez et al., 2017).

With the movement of AIEd and the availability of (colossal) understudy data and learning assessment, Luckin et al. (2016) ensure a "[r] renaissance in evaluation" (p. 35). Computerized reasoning can give without a second to save analysis and assessment. Instead of interruption and-test, AIEd can be consolidated into learning practices for a persistent assessment of understudy achievement. Estimations have been used to envision the probability of an understudy bombarding an errand or leaving a course with huge levels of precision (e.g., Bahadır, 2016).

In their new report, Baker and Smith (2019) approach informational AI mechanical assemblies from three substitute perspectives; a) understudy standing up to, b) teacher going up against, and c) system defying AIEd. Understudy defying AI gadgets are modifying that understudies use to acquire capability with a theme, i.e., flexible or modified learning the board systems or ITS. Teacher standing up to structures are used to help the educator and decrease their duty through automating tasks like association, evaluation, analysis and duplicating distinguishing proof. AIEd contraptions moreover give understanding into the learning progress of understudies so the educator can proactively offer assistance and heading where required. System standing up to AIEd are instruments that offer information to chiefs and bosses on the institutional level, for example to screen trimming down models across assets or colleges.

Concerning high level training, we use the possibility of the understudy life-cycle (see Reid, 1995) as a framework to portray the diverse AI set up organizations regarding the more broad institutional and definitive level, similarly with respect to supporting the academic teaching and learning measure in the more modest sense.

\section{OBJECTIVES}

- To identify the level of awareness of Artificial Intelligence tools used by Management students.

- To identify the usability of Artificial intelligence tools by Management students as per demographic records.

\section{HYPOTHESIS}

H1: Applications of Artificial Intelligence tools used by Management students are same across Gender.

H2: Applications of Artificial Intelligence tools used by Management students are same across Qualifications.

H3: Applications of Artificial Intelligence tools used by Management students are same across Work Experience.

\section{RESEARCH METHODOLOGY}

In order to satisfy the objectives, a descriptive study was carried out. Management students from a reputed institute in Mumbai were considered as primary source for conducting survey with a questionnaire. Convenient sampling is done with 120 as sample size.

Responses were collected to check the level of awareness \& the usability level of the AI tools in learning. Responses were categorized on various demographic characteristics to obtain detailed analysis. SPSS tool was considered for hypothesis testing.

\section{DATA ANALYSIS \\ A. Descriptive Statistics}

Summary Statistics for general awareness of AI tools as per different demographic factors are generated as follows. 


\section{Gender Wise Distribution}

Table 1. Gender Wise Distribution

\begin{tabular}{|c|l|c|}
\hline Sr. No. & Gender & Total \\
\hline 1 & Male & 54 \\
\hline 2 & Female & 66 \\
\hline & Total & $\mathbf{1 2 0}$ \\
\hline
\end{tabular}

\section{Gender Wise Distribution}

- Male -Female

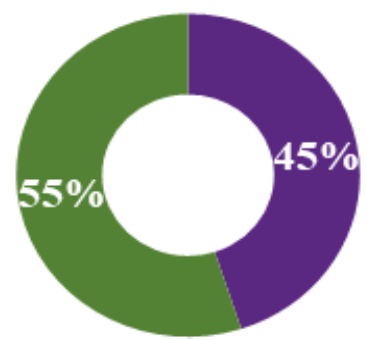

Figure 1. Gender Wise Distribution Chart

2. Qualification Wise Distribution:

Table 2. Qualification Wise Distribution

\begin{tabular}{|c|l|c|}
\hline Sr. No. & Qualification & Total \\
\hline 1 & Engineers & 52 \\
\hline 2 & Non-Engineers & 68 \\
\hline & Total & $\mathbf{1 2 0}$ \\
\hline
\end{tabular}

Qualification Wise Distribution

- Engineers Non-Engineers

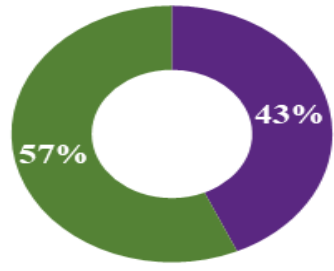

Figure 2. Qualification Wise Distribution Chart

3. Work Experience Wise Distribution

Table 3. Work Experience Wise Distribution

\begin{tabular}{|l|l|l|}
\hline Sr. No. & Experience & Total \\
\hline 1 & Experienced & 28 \\
\hline 2 & Fresher's & 92 \\
\hline & Total & $\mathbf{1 2 0}$ \\
\hline
\end{tabular}




\section{Work Experience Wise Distribution}

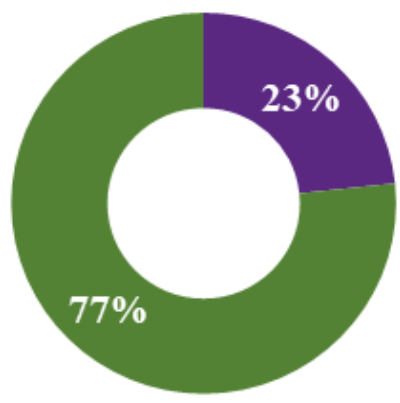

Experienced Fresher

Figure 3. Work Experience Wise Distribution Chart

\section{A. Level of Awareness}

1) Alexa (Amazon)

Table 4. Alexa (Amazon) Awareness

\begin{tabular}{|l|l|l|l|}
\hline Sr.No. & Awareness Level & Total & Percentage \\
\hline 1 & No, I haven't heard nor used this tool & 11 & $9 \%$ \\
\hline 2 & Yes, I have heard about this tool but never used it. & 91 & $76 \%$ \\
\hline 3 & Yes, I have heard about this tool and used it. & 18 & $15 \%$ \\
\hline & Total & $\mathbf{1 2 0}$ & $\mathbf{1 0 0 \%}$ \\
\hline
\end{tabular}

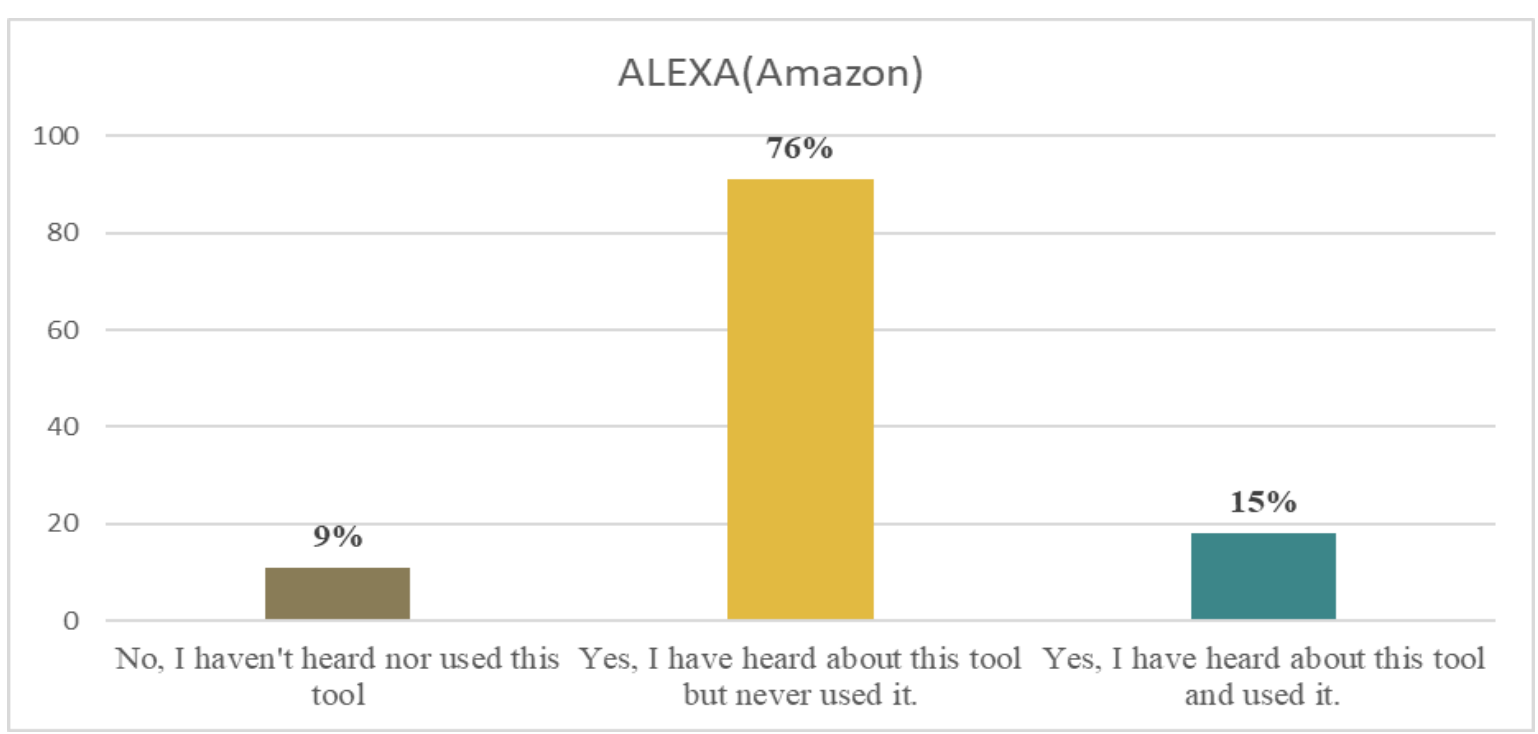

Figure 4. Awareness for Alexa (Amazon)

2) Home (Google)

Table 5. Home (Google) Awareness

\begin{tabular}{|c|l|c|c|}
\hline Sr. No. & Awareness Level & Total & Percentage \\
\hline 1 & No, I haven't heard nor used this tool & 25 & $21 \%$ \\
\hline 2 & Yes, I have heard about this tool but never used it. & 71 & $59 \%$ \\
\hline 3 & Yes, I have heard about this tool and used it. & 24 & $20 \%$ \\
\hline & Total & $\mathbf{1 2 0}$ & $\mathbf{1 0 0 \%}$ \\
\hline
\end{tabular}

www.psychologyandeducation.net 


\section{HOME (Google)}

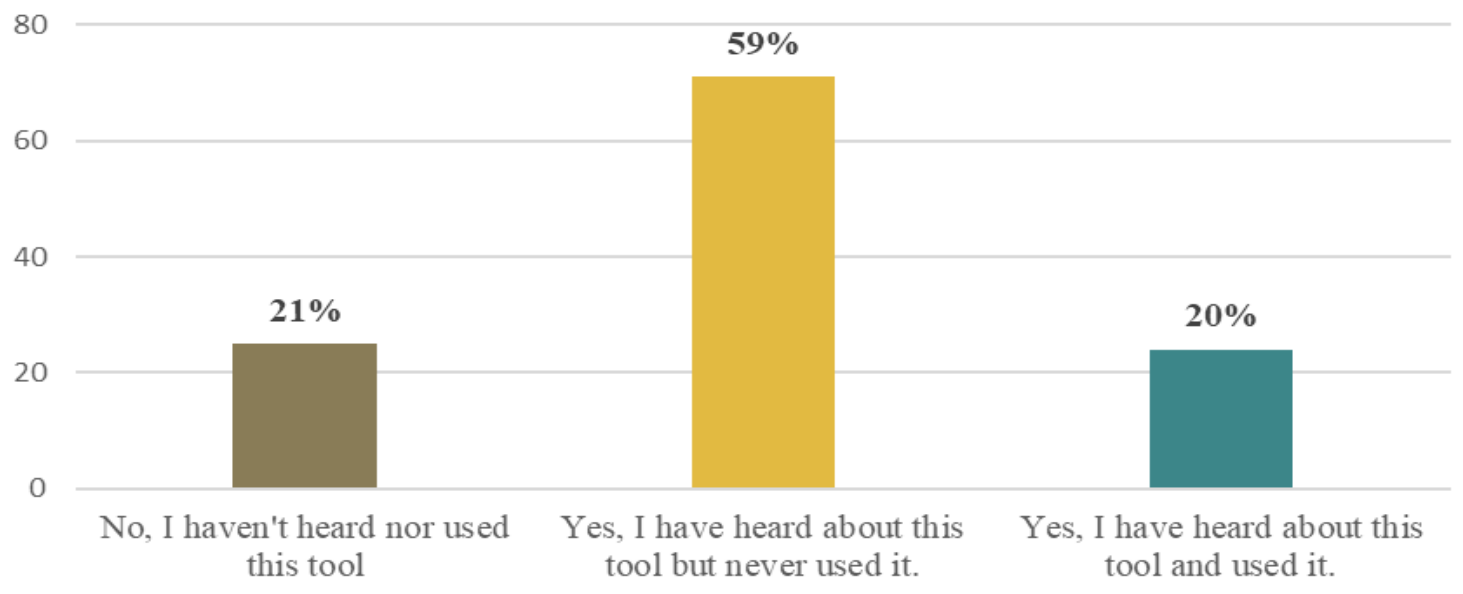

Figure 5. Awareness for Home (Google)

3) Siri (IoS)

Table 6. Siri (IoS) Awareness

\begin{tabular}{|c|l|c|c|}
\hline Sr. No. & Awareness Level & Total & Percentage \\
\hline 1 & No, I haven't heard nor used this tool. & 5 & $4 \%$ \\
\hline 2 & Yes, I have heard about this tool but never used it. & 77 & $64 \%$ \\
\hline 3 & Yes, I have heard about this tool and used it. & 38 & $32 \%$ \\
\hline & Total & $\mathbf{1 2 0}$ & $\mathbf{1 0 0 \%}$ \\
\hline
\end{tabular}

\section{SIRI(IoS)}

100

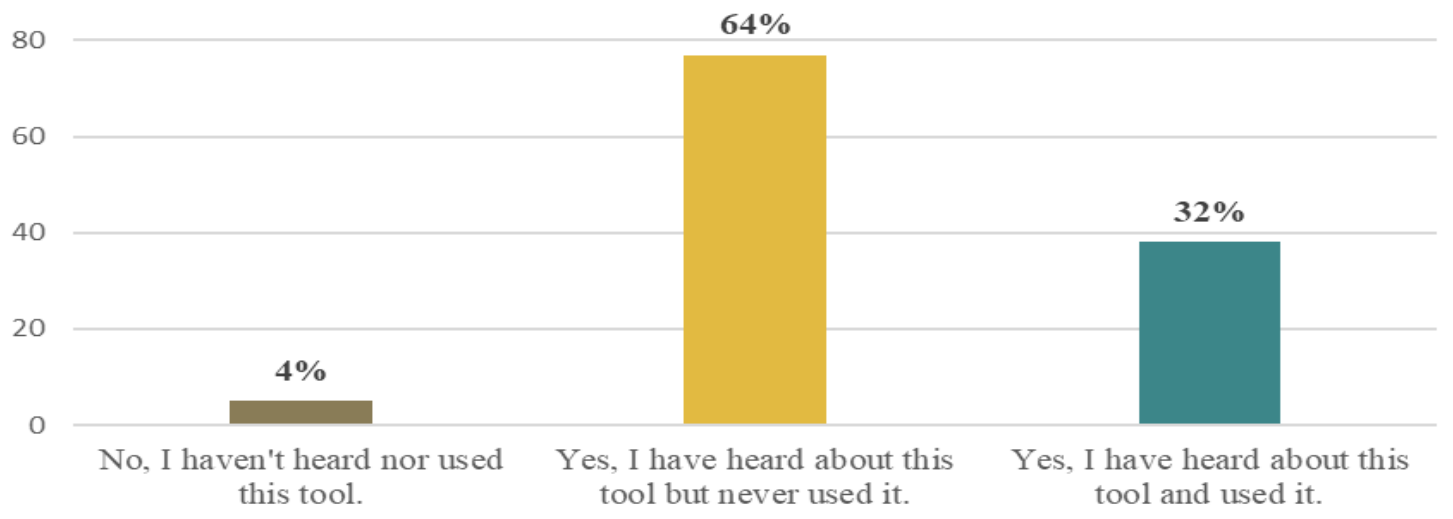

Figure 6. Awareness for Siri (IoS)

\section{4) Grammarly}

Table 7. Grammarly Awareness

\begin{tabular}{|c|l|c|c|}
\hline Sr. No. & Awareness Level & Total & Percentage \\
\hline 1 & No, I haven't heard nor used this tool. & 30 & $25 \%$ \\
\hline 2 & Yes, I have heard about this tool but never used it. & 56 & $47 \%$ \\
\hline 3 & Yes, I have heard about this tool and used it. & 34 & $28 \%$ \\
\hline & Total & $\mathbf{1 2 0}$ & $\mathbf{1 0 0 \%}$ \\
\hline
\end{tabular}




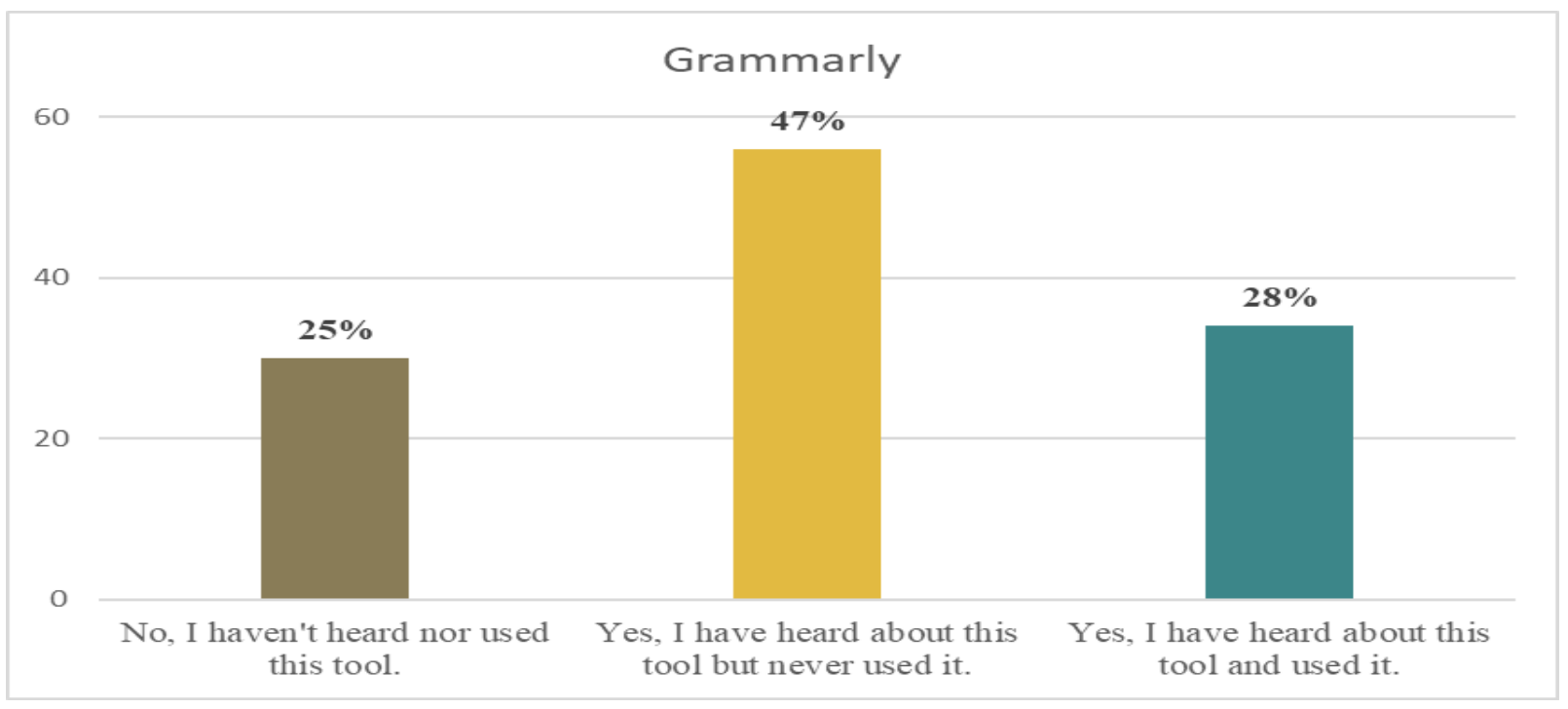

5) Turnitin

Figure 7. Awareness for Grammarly

Table 8. Turnitin Awareness

\begin{tabular}{|c|l|c|c|}
\hline Sr. No. & Awareness Level & Total & Percentage \\
\hline 1 & No, I haven't heard nor used this tool. & 5 & $4 \%$ \\
\hline 2 & Yes, I have heard about this tool but never used it. & 77 & $64 \%$ \\
\hline 3 & Yes, I have heard about this tool and used it. & 38 & $32 \%$ \\
\hline & Total & $\mathbf{1 2 0}$ & $\mathbf{1 0 0 \%}$ \\
\hline
\end{tabular}

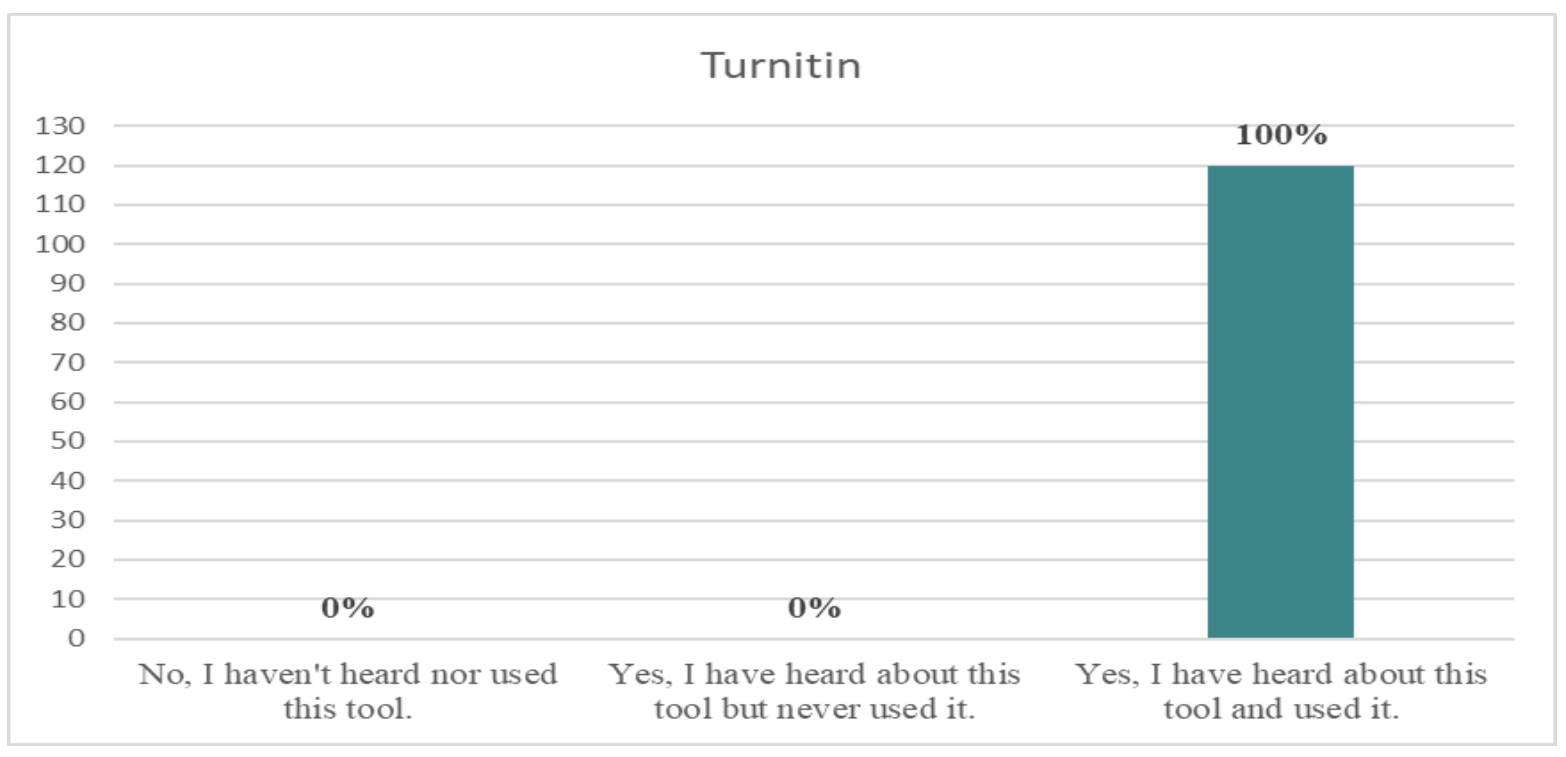

Figure 8. Awareness for Turnitin

6) Overall Awareness

Table 9. Overall Awareness

\begin{tabular}{|l|c|c|c|c|c|c|c|}
\hline & Low & Medium & High & Total & Low\% & Medium\% & High\% \\
\hline Alexa (Amazon) & 11 & 91 & 18 & 120 & $9 \%$ & $76 \%$ & $15 \%$ \\
\hline Home (Google) & 25 & 71 & 24 & 120 & $21 \%$ & $59 \%$ & $20 \%$ \\
\hline SIRI & 5 & 77 & 38 & 120 & $4 \%$ & $64 \%$ & $32 \%$ \\
\hline
\end{tabular}

www.psychologyandeducation.net 


\begin{tabular}{|l|c|c|c|c|c|c|c|} 
Grammarly & 30 & 56 & 34 & 120 & $25 \%$ & $47 \%$ & $28 \%$ \\
\hline Turnitin & 0 & 0 & 120 & 120 & $0 \%$ & $0 \%$ & $100 \%$ \\
\hline Total & 71 & 295 & 234 & 600 & & & \\
\hline
\end{tabular}

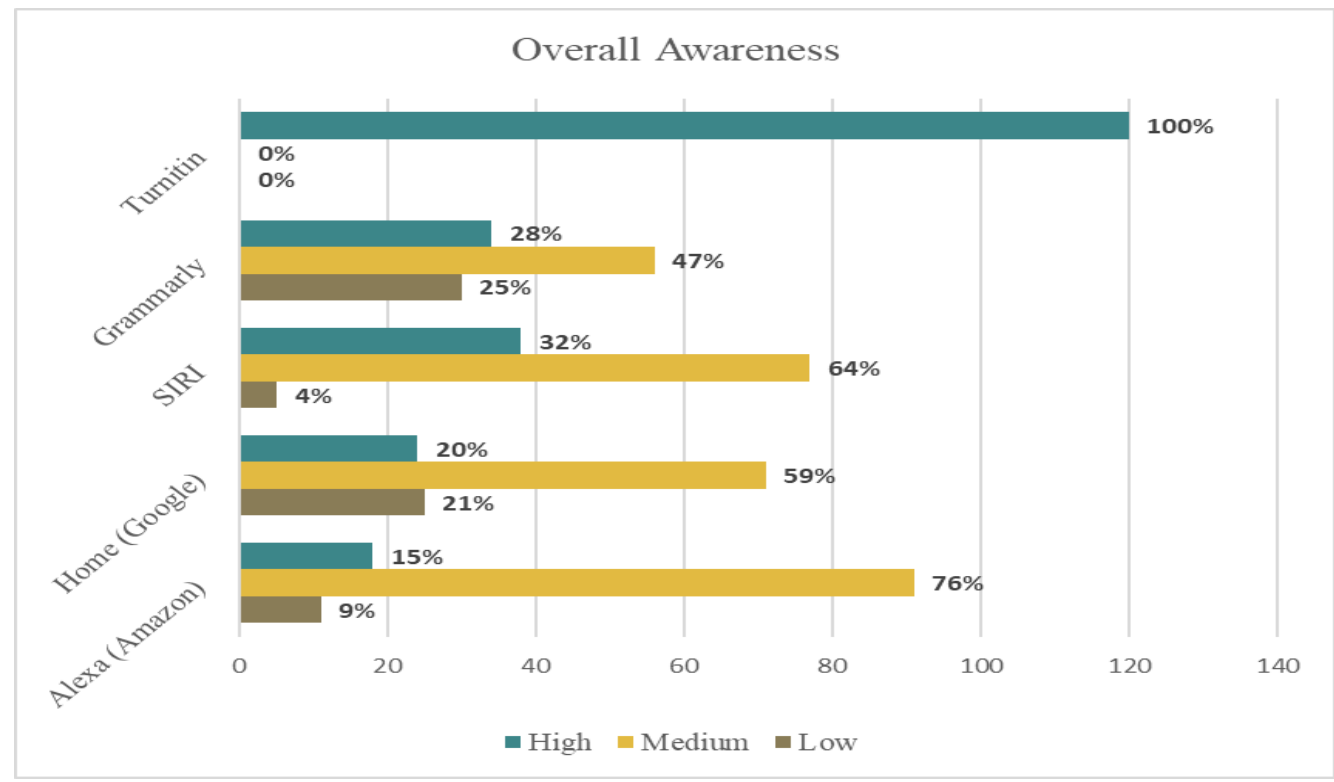

Figure 9. Overall Awareness

B. Hypothesis Testing

1) T-test for gender wise analysis

Table 10. Gender wise group statistics

\begin{tabular}{|c|c|c|c|c|c|}
\hline \multicolumn{6}{|c|}{ Group Statistics } \\
\hline & Gender & $\mathrm{N}$ & Mean & Std. Deviation & Std. Error Mean \\
\hline \multirow{2}{*}{ Total } & $\mathrm{M}$ & 66 & 12.30 & 2.925 & .360 \\
\cline { 2 - 6 } & $\mathrm{F}$ & 54 & 11.66 & 2.761 & .416 \\
\hline
\end{tabular}

Table 11. Independent sample test for gender

\begin{tabular}{|c|c|c|c|c|c|c|c|}
\hline \multicolumn{8}{|c|}{ Independent Samples Test } \\
\hline \multirow[t]{2}{*}{ Equal variances } & \multicolumn{2}{|c|}{$\begin{array}{l}\text { Levene's Test } \\
\text { for Equality of } \\
\text { Variances }\end{array}$} & \multicolumn{5}{|c|}{ t-test for Equality of Means } \\
\hline & $\mathbf{F}$ & Sig. & $\mathbf{t}$ & dff & Sig & $\begin{array}{c}\text { Mean } \\
\text { Diff. }\end{array}$ & $\begin{array}{l}\text { Std. } \\
\text { Error } \\
\text { Diff. }\end{array}$ \\
\hline Assumed & .161 & .689 & 1.867 & 118 & .064 & .985 & .528 \\
\hline Not Assumed & & & 1.882 & 112.784 & .062 & .985 & .524 \\
\hline
\end{tabular}

Since the Sig. value for Qualification Wise analysis is greater than 0.05 , we accept the null hypothesis.

2) T-test for experience wise analysis

Table 12. Experience wise group statistics

\begin{tabular}{|c|c|c|c|c|c|}
\hline \multicolumn{7}{|c|}{ Group Statistics } \\
\hline & Experienced & N & Mean & Std. Deviation & Std. Error Mean \\
\hline \multirow{2}{*}{ Total } & $\mathbf{1}$ & $\mathbf{2 8}$ & $\mathbf{1 2 . 1 8}$ & $\mathbf{3 . 0 9 2}$ & $\mathbf{. 5 8 4}$ \\
\cline { 2 - 6 } & $\mathbf{0}$ & $\mathbf{9 2}$ & $\mathbf{1 2 . 2 0}$ & $\mathbf{2 . 8 4 9}$ & .297 \\
\hline
\end{tabular}


Table 13. Independent sample test for experience

\begin{tabular}{|c|c|c|c|c|c|c|c|}
\hline \multicolumn{8}{|c|}{ Independent Samples Test } \\
\hline \multirow[t]{2}{*}{ Equal variances } & \multicolumn{2}{|c|}{$\begin{array}{c}\text { Levene's Test for } \\
\text { Equality of } \\
\text { Variances } \\
\end{array}$} & \multicolumn{5}{|c|}{ t-test for Equality of Means } \\
\hline & $\mathbf{F}$ & Sig. & $\mathbf{t}$ & df & Sig & $\begin{array}{c}\text { Mean } \\
\text { Diff. }\end{array}$ & $\begin{array}{l}\text { Std. } \\
\text { Error } \\
\text { Diff. }\end{array}$ \\
\hline Assumed & .542 & .463 & -.027 & 118 & .978 & -.017 & .627 \\
\hline Not Assumed & & & -.026 & 41.924 & .979 & -.017 & .655 \\
\hline
\end{tabular}

Since the Sig. value for Experience Wise analysis is greater than 0.05 , we accept the null hypothesis.

\section{FINDINGS}

Results are as follows:

\section{Alexa (Amazon)}

- $9 \%$ of the students haven't heard nor used this tool

- $76 \%$ of the students have heard about this tool but never used it.

- $15 \%$ of the students have heard about this tool and used it.

\section{Home (Google)}

- $21 \%$ of the students haven't heard nor used this tool

- $59 \%$ of the students have heard about this tool but never used it.

- $20 \%$ of the students have heard about this tool and used it.

\section{Siri (IoS)}

- $4 \%$ of the students haven't heard nor used this tool

- $64 \%$ of the students have heard about this tool but never used it.

- $32 \%$ of the students have heard about this tool and used it.

\section{Grammarly}

- $25 \%$ of the students haven't heard nor used this tool

- $47 \%$ of the students have heard about this tool but never used it.

- $28 \%$ of the students have heard about this tool and used it.

\section{Turnitin}

- $0 \%$ of the students haven't heard nor used this
- $0 \%$ of the students have heard about this tool but never used it.

- $100 \%$ of the students have heard about this tool and used it.

Further the interpretation on analysis of awareness levels, based on hypothesis testing is as follows:

1. There is no significant difference between the levels of awareness of AI tools used in Management education in Management students across Gender.

2. There is no significant difference between the levels of awareness of AI tools used in Management education in Management students across Qualifications.

3. There is no significant difference between the levels of awareness of AI tools used in Management education in Management students across Experience.

\section{CONCLUSIONS}

It is observed that,

- Majority of the management students are highly aware about the Turnitin as AI tool \& have used in management education.

- Majority of the Management students are aware about Alexa (Amazon), Home (Google), SIRI \& Grammarly as AI tools but haven't applied it management education.

- Application of Artificial Intelligence tools for Management Students is not dependent on Gender

- Application of Artificial Intelligence tools for Management Students is not dependent on Qualification

- Application of Artificial Intelligence tools for Management Students is not dependent 
on Work

In the current phase of digitization and Industry Revolution, it is very important for everyone to be in pace with the changing trends. Students need to be skilled with such technical advances which can help them in applying / utilizing these features in real world application after completion of their specialized courses. The results show that there isn't significant difference in awareness level when students are segregated based on various parameters like gender, qualification or experience. So, it can be concluded that there are no specific criteria for gaining knowledge of such technical advancements.

\section{LIMITATIONS}

The results have been drawn after doing analysis based on survey results collected from reputed management institute students. This limits the study to awareness of the AI tools in Management Education in management students of a reputed management institute. The scope could have been extended to the management students of all of the management institutes in a particular region/city. Also, it can be extended to all the post-graduate students of various institutes who are involved in use of such Microsoft office tools which include students doing MCA / M.E. / M. TECH / M.Sc. etc.

\section{REFERENCES:}

- Aleven V., Holstein K. \& McLaren B.M. (2017). "Intelligent tutors as teachers' aides: exploring teacher needs for real-time analytics in blended classrooms", ACMDL, Vancouver, British Columbia, Canada. pp. 257-266. Web. 20 Jan. 2021.

- $\quad$ Aleven V., Koedinger K.R., McLaren B.M. \& Sewall J. (2019). "A new paradigm for intelligent tutoring systems: example-tracing tutors". International Journal of Artificial Intelligence in Education. pp. 105-154. Web. 20 Jan. 2021.

- $\quad$ Brett Williams. (2019, June 21). "Ditch your keyboard in 20 languages with Microsoft's new dictation app". MashableIndia. Web. 22 Jan. 2021. <https://mashable.com/2017/06/20/microsof t-dictate-app/\#ye2xxT_qz5ql/dictate>

- Bostrom N, \& Yudkowsky. (2011). "The Ethics of Artificial Intelligence.” Cambridge handbook of Artificial Intelligence. pp.
316-334. Web. 20 Jan. 2021.

- Clancey W. J. (1979). "Tutoring rules for guiding a case method dialogue, in Intelligent Tutoring Systems." International Journal of Man-Machine Studies. pp. 201-225. Web. 22 Jan. 2021.

- CyberText Consulting. (2017, May 03). "Word: List keyboard shortcuts, auto text, and autocorrect entries." CyberText. Web. $20 \quad$ Jan. 2021. <https://cybertext.wordpress.com/2017/05/0 3/word-list-keyboard-shortcuts-autotext-and -autocorrect-entries/>

- Dan Gookin. (n.d). "How to Use AutoCorrect in Word 2016." Dummies. Web. $20 \quad$ Jan. 2021. <https://www.dummies.com/software/micro soft-office/word/how-to-use-autocorrect-inword-2016/>

- Daniel Faggella. (2019, May 20). "AI for Voice Transcription - Comparing Upcoming Startups and Established Players." Emerj. Web. 20 Jan. 2021. $<$ https://www.techemergence.com/ai-for-voi ce-transcription/>

- Dewan A. (2010). "Scope Of Technology In Higher Education In India: A Study." IEEE Xplore. Web. 20 Jan. 2021.

- Gutierrez-Santos S., Mavrikis M., \& Poulovassilis A. (2016). "Design and evaluation of teacher assistance tools for exploratory learning environments." ACM DL. Edinburgh. United Kingdom. pp. 168-172. Web. 20 Jan. 2021.

- $\quad$ O'Shea T. (1979). "Self Improving Teaching Systems." Birkhauser-Verlag. Web. 20 Jan. 2021.

- $\quad$ Tech ON THE Net. (n.d). "MS Excel 2010: Turn off AutoCorrect." TechONTHENet. Web. $20 \quad$ Jan. 2021. <https://www.techonthenet.com/excel/quest ions/auto_correct2010.php>

- Yacef K. (2002). "Intelligent teaching assistant systems." IEEE Xplore. pp. 136-140. Web. 20 Jan. 2021.

- Alexandre Gonfalonieri. "How Amazon Alexa works? Your guide to Natural Language Processing (AI)." Towards data science. 21 Nov 2018. Web. 20 Jan. 2021. 
<https://towardsdatascience.com/how-amaz on-alexa-works-your-guide-to-natural-langu age-processing-ai-7506004709d3>

- "What Is Conversational AI?" Amazon alexa. Web. 20 Jan. 2021. $<$ https://developer.amazon.com/en-US/alexa /alexa-skills-kit/conversational-ai>

- Nest. Web. 20 Jan. 2021. <https://nest.com/>

- Andrew Gebhart. "Everything you want to know about Google Home." Cnet. Web. 20 Jan.

2021.

$<$ https://www.cnet.com/how-to/everything-y ou-want-to-know-about-google-home/>

- Apple. Web. 20 Jan. 2021. $<$ https://developer.apple.com/design/human -interface-guidelines/siri/overview/introduct ion/>

- "How Does Grammarly Work?" Grammarly Blog. Web. 20 Jan. 2021. <https://www.grammarly.com/blog/how-do es-grammarly-work/>

- "How Teachers Can Prepare for AI-Based Writing." Turnitin. Web. 20 Jan. 2021. $<$ https://www.turnitin.com/blog/how-teache rs-can-prepare-for-ai-based-writing > 